\title{
O Uso da Primeira Pessoa do Plural na Fala de Londrina
}

\author{
El Uso de la Primera Persona del Plural en el Habla de Londrina
}

Fidel PASCUA Vílchez *

Resumo: O presente trabalho visa descrever as diferentes variantes usadas em Londrina para se referir à primeira pessoa do plural na função de sujeito. Além do pronome pessoal nós, o português brasileiro incorpora um sintagma nominal, a gente, capaz de cumprir também essa função. Embora ambas tenham como referente a primeira pessoa do plural, a concordância com o verbo é distinta em cada caso. Às vezes também é possível achar uma discordância entre o sujeito nós e o verbo em terceira pessoa do singular que, embora não sendo gramaticalmente correta, é totalmente comunicativa. Através de uma pesquisa de campo, se mapeia a incidência das quatro possibilidades de expressão da primeira pessoa do plural, analisando registros de diversa procedência.

Palavras-chave: Primeira pessoa do plural; Pronomes pessoais; Descrição e análise linguísticas.

Resumen: El presente trabajo aborda las diferentes variantes que se usan en portugués para referirse a la primera persona del plural, cuando ésta cumple la función de sujeto de la oración. Además de pronombre nós, el portugués brasileño incorpora un sintagma nominal a gente, capaz de cumplir también esa función sintáctica. A veces también se puede encontrar la discordancia entre el sujeto nós y el verbo en tercera persona del singular, lo cual, a pesar de no ser gramaticalmente correcto, es totalmente comunicativo. A través de una investigación de campo se

\footnotetext{
* Doutorando em Estudos da Linguagem na Universidade Estadual de Londrina. Contato: aidoiketes@hotmail.com.
} 
intenta conocer la incidencia de las cuatro posibilidades de expresión de la primera persona del plural en el habla de Londrina, analizando registros de diversa procedencia.

Palabras Clave: Primera persona del plural; Pronombres personales; Descripción y análisis lingüísticas.

\section{Objetivos}

O principal objetivo deste trabalho é conhecer a preferência no uso das distintas maneiras de poder se referir à primeira pessoa do plural em função sintática de sujeito (nós + verbo em primeira pessoa do plural; a gente + verbo em terceira pessoa do singular; nós + verbo em terceira pessoa do singular; a gente + verbo em primeira pessoa do plural) na fala dos habitantes de Londrina.

Os resultados obtidos permitirão no caso estabelecer se existem padrões de uso de cada uma das formas em função da ocupação, idade, sexo, formação dos informantes, etc.

\section{Metodologia}

Fez-se uma coleta de amostras de atos de fala em situações reais de pessoas moradoras de Londrina ou que atuam diariamente em nossa cidade, pois o objeto de estudo, a primeira pessoa do plural, é um elemento muito frequente no cotidiano da fala das pessoas. Os inquéritos foram feitos a atendentes de lojas, restaurantes, lotéricas e comerciantes, com a aplicação da pergunta: "Vocês aceitam cartão?" A pergunta foi escolhida com o objetivo de provocar o uso da primeira pessoa do plural numa situação de fala real, já que às vezes as pessoas escolhidas para a tomada das amostras perceben que estão sendo analisadas e agem de maneira artificial e as suas respostas não são espontáneas. A consequência disso é que os resultados obtidos não correspondem com a realidade do uso da língua. É bem melhor ir provido de um caderninho e uma caneta e ir anotando, discretamente, as produções naturais dos informantes sem eles saberem que estão sendo analisados.

Foram tomadas 50 amostras com as quais foi feita a análise posterior para tirar as conclusões pertinentes. 


\section{0 pronome}

O pronome é uma categoría gramatical cuja caraterística fundamental é a de substituir o nome. Dentre dos pronomes existem os chamados pronomes pessoais, os que têm como referente uma pessoa, animal ou coisa. Os pronomes pessoais aludem às pessoas que fazem parte do discurso. A primeira pessoa é a que fala de si própria, a segunda pessoa é a que é interpelada diretamente pela pessoa que fala e a terceira pessoa é a pessoa de quem se fala. Cada uma dessas pessoas pode ser uma (singular) ou várias (plural). O objeto deste artigo científico é a primeira pessoa do plural.

\section{A morfologia e a história do pronome}

O sistema dos pronomes pessoais em português, como acontece com todas as línguas românicas é um remanescente do sistema casual latino. No latim, a mesma palavra muda a sua terminação segundo a função sintática que desempenha na oração e, desse jeito, achamos formas distintas quando a palavra desempenha a função de sujeito (nominativo), vocativo, complemento direto (acusativo), complemento de um nome (genitivo), complemento indireto (dativo) e complemento circunstancial (ablativo). É por isso que existem em português as formas eu, me, mim, comigo; tu, te, ti, contigo; ele, ela, o, a, lhe; se, si consigo; nós, nos, conosco, vós, vos convosco; eles, elas, os, as, lhes. No caso dos pronomes da primeira pessoa do plural existiam: i) nos para o nominativo, vocativo e acusativo; ii) nostrum o nostri para o genitivo (o que da origem ao nosso possessivo); iii) nobis para o dativo e ablativo e iv) um ablativo de companhia nobiscum. Herdeiras destas formas são as nossas do português nós e nos, as quais são pronunciadas [nos] ou ás vezes [nojs], e as formas nosco [nósku] do português antigo e conosco [kunósku], derivada de com nosco.

Como já foi dito, os pronomes pessoais tem o traço de pessoa e compartilham esta caraterística com as formas verbais. É assim que conjugamos um pronome de primeira, segunda ou terceira pessoa do singular ou de plural com a sua forma verbal correspondente. Um exemplo: eu amo, tu amas, ele ama, nós amamos, vós amais, eles amam.

Mas a língua é um elemento vivo, continuamente em evolução e influenciável por fatores que vão além das regras morfológicas e 
sintáticas. Temos em português que o pronome majoritariamente usado para a segunda pessoa do singular, o você, é conjugado com a forma verbal de terceira pessoa do singular (você ama), pois deriva de um sintagma Vossa mercê que precisava da terceira pessoa do verbo. O mesmo acontece com o pronome de segunda pessoa do plural, vocês, que é conjugado com a forma de terceira pessoa do plural (vocês amam). Ainda, por questões pragmáticas, podem ser substituídos pelas formas nominais de respeito o senhor, a senhora, os senhores, as senhoras.

No caso da primeira pessoa do plural, no português brasileiro, está já totalmente assimilado o sintagma a gente para se referir a nós, com a vantagem de que pode aparecer cumprindo qualquer uma das funções sintáticas na oração sem mudar a sua forma, o que faz dessa forma um elemento muito produtivo em termos de capitalismo linguístico (maior produção, menor custo) e isso faz com que paulatinamente vá-se impondo às outras formas pronominais, de morfologia mais complexa.

Junta-se a isso que a conjugação verbal está evoluindo também muito rápido e a terceira pessoa do singular vai ganhando terreno em detrimento das outras formas verbais na fala coloquial, com excepção da primeira pessoa do singular, mesmo não existindo às vezes concordância entre o sujeito e o verbo. Estes fenômenos que começam sempre nos níveis diastráticos de mais baixa escolaridade acabam invadindo níveis de escolaridade mais alta até se expandir por completo e não surprende mais ouvir coisas como nós falou ou nós vai, tão frequentes no uso, inclusive por pessoas de não necessariamente nível de escolaridade baixa e com estudos superiores até.

O presente trabalho mapeia justamente as quatro possibilidades de uso anteriormente descritas: nós + verbo em primeira pessoa do plural, a gente + verbo em terceira pessoa do singular, nós + terceira pessoa do singular e a gente + primeira pessoa do plural (u.e.: nós vamos, a gente vai, nós vai, a gente vamos).

\section{A norma e o uso da primeira pessoa do plural}

Os pronomes pessoais são apresentados sem muitas diferenças pelas gramáticas normativas. Com frequência não são incluídas as formas mais comuns utilizadas na fala coloquial, como acontece com 
o você, vocês, a gente. Às vezes a classificação é controvertida até, já que o sintagma a gente pode ser considerado um pronome em algumas gramáticas, ou como uma forma de tratamento em outras, ou como um pronome indefinido, comentado em rodapé. Também não fica muito claro o número dele, por ser morfológicamente singular, mas ter um referente coletivo.

A noção de número implica o agrupamento de elementos da mesma natureza, o que não acontece com o pronome nós, já que não pode ser considerado a soma de vários eus, salvo que quem fale sofra de esquizofrenia. Nesse caso, poderia se falar de vários eus, dentro de uma mesma pessoa.

\section{Análise dos dados}

Obteve-se um total de 50 dados, sendo 17 de nós (34\%), 20 de a gente (40\%), 8 de sujeito $\varnothing$ com verbo na primeira pessoa do plural $(16 \%), 3$ de sujeito $\varnothing$ com verbo em terceira pessoa do singular $(6 \%)$, 2 com sujeito nós e verbo em terceira pessoa do singular (4\%) e não houve ocorrências de a gente com verbo em primeira pessoa do plural $(0 \%)$. Dos 50 dados, 38 são de mulheres e 12 de homens. Quanto à idade, a distribuição foi a seguinte: 14 tinham até 20 anos, 21 iam dos 21 até os 30 anos, 13 pessoas eram da faixa entre os 31 e os 40 e, finalmente, 2 tinham entre 40 e 50 anos.

Os resultados mostram uma incidência maior da forma a gente aceita, que teve um total de 19 respostas; em segundo lugar aparece a forma nós aceitamos, com 17 respostas, ambas gramaticalmente corretas e com sujeito explícito. Depois, a forma com sujeito implícito aceitamos tem uma incidência menor, com um total de 9 respostas e aparecem duas formas não gramaticais aceita (3 respostas) e nós aceita (2 respostas). 


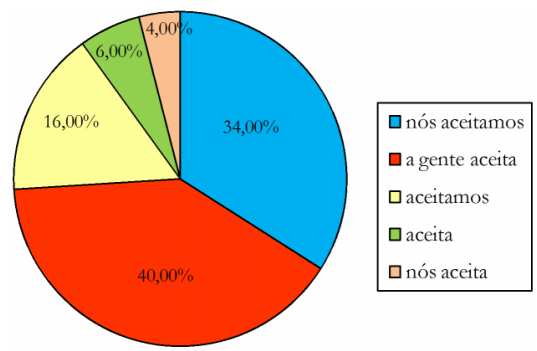

Gráfico 1 - Respostas ao inquérito: "Vocês aceitam carttão?"

\section{Análise com base na variável sexo}

Como foi anteriormente dito foram inquiridos 38 mulheres e 12 homens, uma vez que as pessoas que trabalham no lugar onde foram feitos os inquéritos (o Shopping Center Catuaî) são em sua grande maioria mulheres. Porém tentou-se também obter respostas de atendentes masculinos.

A forma a gente aceita teve 11 respostas das mulheres e 8 dos homens; a forma nós aceitamos teve 11 das mulheres e 6 respostas dos homens; a forma aceitamos foi mais usada pelos homens (5 vezes) do que pelas mulheres (4 vezes). As formas aceita e nós aceita foram empregadas unicamente por mulheres (três vezes no primeiro caso e dois no segundo). Pode-se ver mais claramente no gráfico 2:

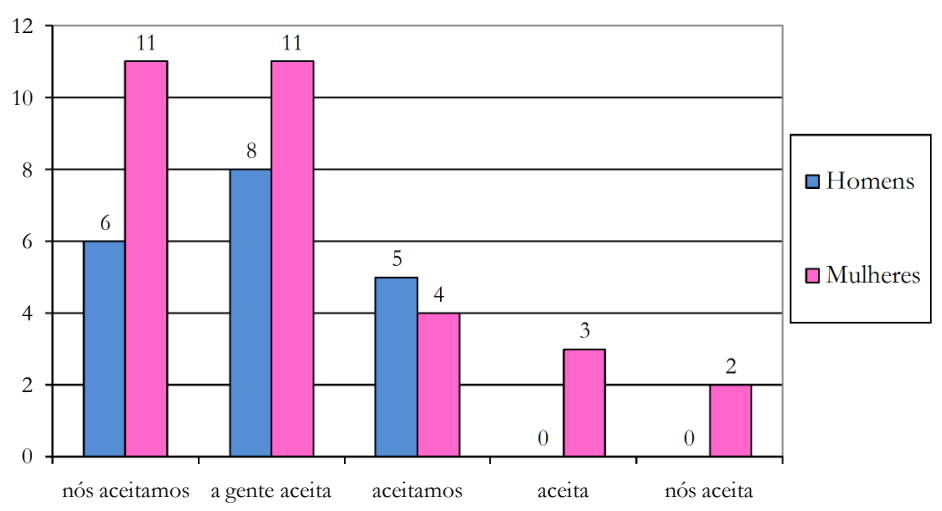

Gráfico 2 - Respostas por sexos 
Quanto às porcentagens por sexos, a forma predominante entre os homens foi a gente aceita (42,11\%), seguido de nós aceitamos (31,58\%) e aceitamos (26,32\%). As duas formas restantes recolhidas no inquérito, aceita e nós aceita, foram exclusivamente de uso pelo gênero feminino. Pode-se comprovar melhor nos gráficos 3 e 4 :

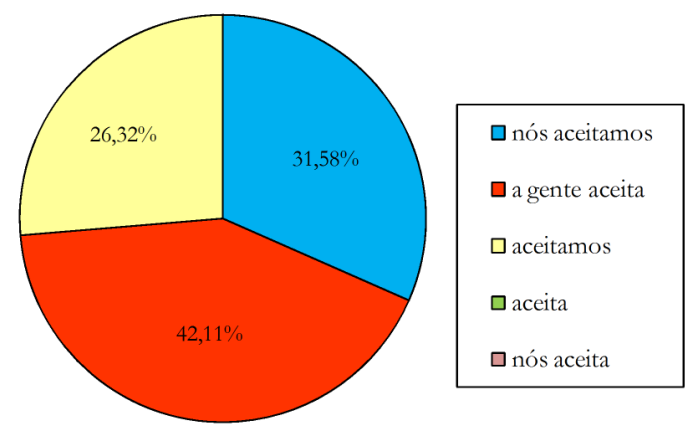

Gráfico 3 - Análise com base na variável sexo-Homens

Quanto às mulheres, as formas a gente aceita e nós aceitamos obtiveram o mesmo número de respostas (11 para cada uma delas), o que deu uma porcentagem do $35,48 \%$ respectivamente; seguiu em terceiro lugar a forma aceitamos com 4 respostas (12, 90\%); aceita com 3 respostas $(9,68 \%)$ e nós aceita 2 respostas $(6,45 \%)$.

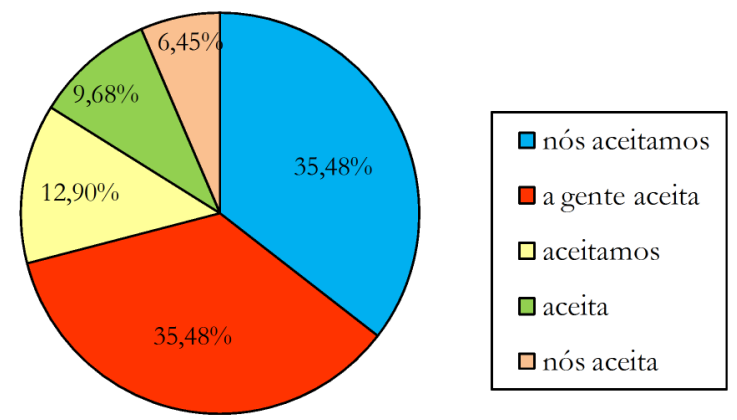

Gráfico 4 - Análise com base na variável sexo-Mulheres 


\section{Análise com base na variável faixa etária}

Os atendentes que responderam ao inquérito da pesquisa foram divididos em 4 faixas etárias: até 20 anos, de 21 a 30, de 31 a 40 e acima dos 40. Para esta última faixa etária só se incluem 2 dados recolhidos. A razão disso é que a maioria das pessoas que trabalham no Shopping Catuaí são novas.

\subsection{Até 20 anos:}

O mais relevante da análise desta faixa etária é comprovar o uso predominante da forma com o sujeito "a gente" seguido do verbo em terceira pessoa do singular, que atingiu um nível do $57,14 \%$ (8 vezes), ultrapassando amplamente a metade dos informantes inquiridos, o que permite afirmar que, segundo os resultados obtidos, as pessoas mais novas preferem o uso desta forma sobre as outras descritas.

Parece existir uma relação aparente entre a idade dos inqueridos e a escolha na resposta que eles dão; aliás, nós poderiamos prever o uso da forma "a gente" como sujeito e o verbo concordando em terceira pessoa do singular quando a pessoa que fala é muito nova.

O segundo lugar entre as pessoas de até vinte anos é ocupado pela forma "nós aceitamos" seguida do verbo em primeira pessoa do plural, que obteve um 21,43\% (3 vezes). Depois vem a forma com sujeito implícito "aceitamos", que chegou a 14,29\% (2 vezes); houve também uma resposta com o sujeito "nós" e o verbo em terceira pessoa do singular, o 7,14\% e não houve nenhuma resposta do tipo "aceita" $0,0 \%$.

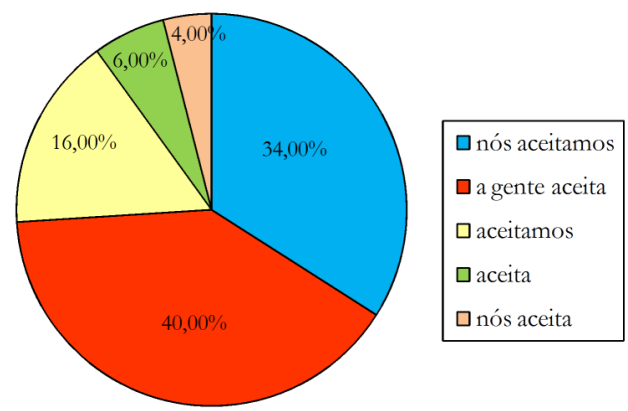

Gráfico 5 - Análise com base na variável faixa etária-até 20 anos 


\subsection{De 21 a 30 anos:}

Dentro desta faixa etária, se obteve o mesmo número de respostas para "nós aceitamos" e para "a gente aceita", foram sete respostas para cada uma dessas duas variantes, o que supõe um 33,33\% em ambos os casos. Segue, a certa distância, a forma sem sujeito explícito "aceitamos", com 4 respostas $(19,05 \%)$ e depois as duas formas não padrão do ponto de vista exclusivamente gramatical "aceita", com duas respostas $(9,52 \%)$ e "nós aceita" com mais uma resposta $(4,76 \%)$.

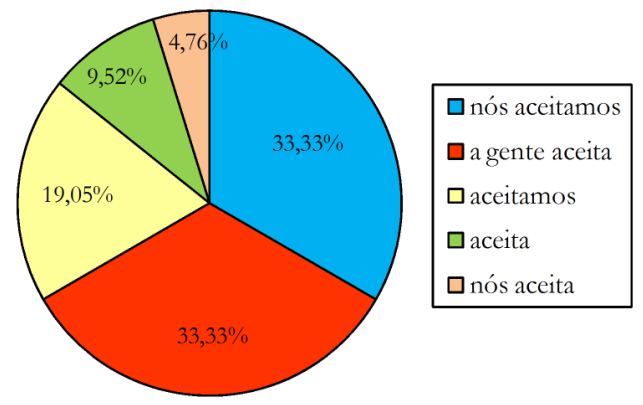

Gráfico 6 - Análise com base na variável faixa etária - de 21a 30 anos

\subsection{De 31 a 40 anos:}

Nesta faixa etária acontece um fato que chama muito a atenção: o uso majoritário da forma "nós aceitamos", que obteve sete respostas (53,85\%). Bem longe fica a segunda opção "a gente aceita", que foi obtida três vezes $(23,08 \%)$, apenas mais uma vez do que a terceira forma preferida "aceitamos" (15,38\%), que foi dada duas vezes e, finalmente, "aceita" apareceu uma só vez (7,69\%). Porém, a forma "nós aceita" não ocorreu dentro desta faixa etária $(0,0 \%)$.

Pelo visto, parece existir alguma relação também, nesse caso, entre a idade dos informantes e os resultados obtidos em suas entrevistas, tal como acontecia com a faixa etária dos mais novos (até 20 anos). Se estes últimos preferiam em sua maioria o uso de "a gente", com o verbo em terceira pessoa do singular, as pessoas que têm mais maturidade optam pela forma em primeira pessoa do plural, seja com 
sujeito explícito ou não, pois, se adicionarmos as sete vezes que ocorreu "nós aceitamos" e as duas de "aceitamos" atingem o número de nove respostas para a primeira pessoa do plural.

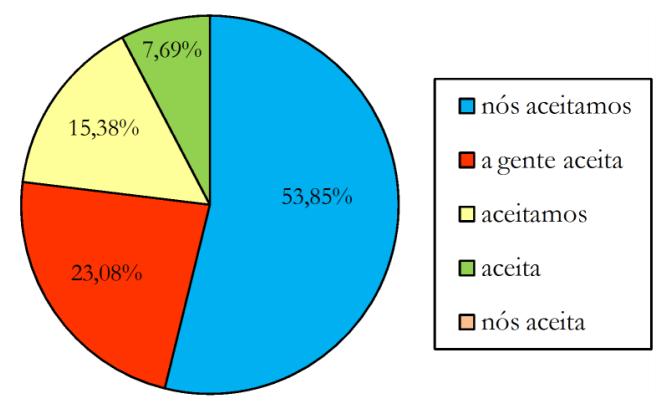

Gráfico 7 - Análise com base na variável faixa etária-de 31 a 40 anos

\subsection{Mais de 40 anos:}

Dentro desta faixa etária obtivemos só duas respostas dos informantes, pela razão dita anteriormente: realmente não existem muitas pessoas trabalhando no lugar do inquérito que ultrapassem os quarenta anos e trabalhem de atendentes. É bem sabido que os donos das lojas, os comerciantes em termos gerais, preferem ter como atendentes moços e, principalmente, mulheres jovens, e ainda melhor se forem lindas. Isso não significa que o atendimento va ser melhor ou a pessoa esteja mais capacitada para desenvolver o seu trabalho, mas para aqueles é bem mais importante dar uma boa imagem. Mesmo assim, as duas respostas obtidas apresentaram uma ocorrência de $a$ gente aceita e uma de aceitamos. Por razões óbvias, se omite a representação gráfica dos resultados, já que não faria muito sentido mostrar um gráfico com apenas duas respostas dos informantes.

\section{Análise por nível de escolaridade}

Foram estrevistados informantes pertencentes a três níveis de escolaridade. Seis deles tinham acabado os estudos primários, outros 26 possuiam estudos secundários terminados e 18 estavam estudando na universidade, mas nenhum deles tinha concluido o curso superior. 


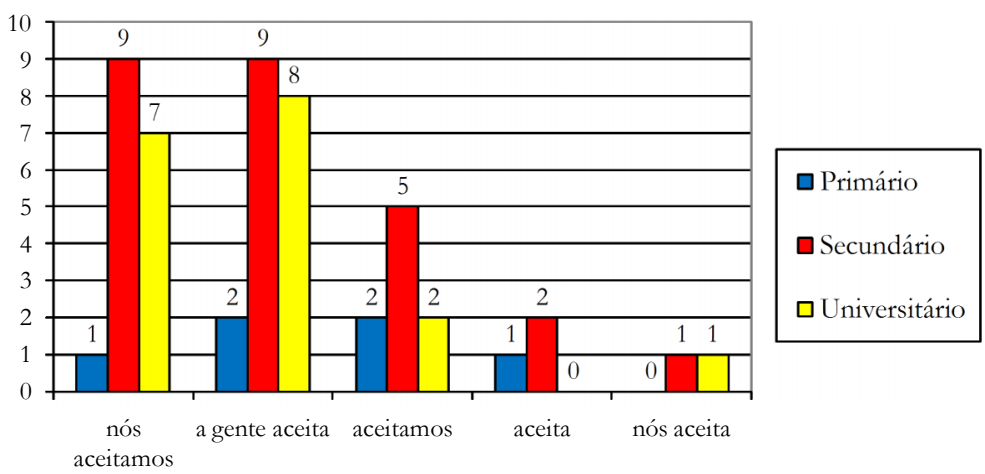

Gráfico 8 - Análise por nível de estcolaridade

Os resultados com base no nível de escolaridade dos informados foi o seguinte: a forma "nós aceitamos" obteve só uma resposta entre os que possuíam estudos primários, porém foi a escolhida majoritariamente pelos informantes que possuíam nível médio, com um total de nove respostas. Os universitários escolheram "nós aceitamos" em sete ocasiões; a forma "a gente aceita" obteve duas respostas dos informantes com nível básico, 9 dos que possuíam estudos secundários e 8 dos universitários; a forma com sujeito implícito de primeira pessoa do plural "aceitamos" foi escolhida duas vezes pelos informantes com nível primário; cinco pelos informantes com estudos secundários e duas pelos universitários; a forma com sujeito implícito de terceira pessoa do singular "aceita" foi escolhida uma vez pelos informantes com nível de estudos mais baixo, duas pelos de nível secundário e nenhuma pelos univesitários e, finalmente, a forma agramatical "nós aceita" foi escolhida por um informante de nível secundário e outra por um informante universitário. Este último dado pode surpreender até, mas, na verdade, só vem confirmar que o uso do sintagma agramatical "nós" + verbo em terceira pessoa do singular está já bem extendido por todos os segmentos da população.

\subsection{Informantes com estudos de nível primário}

Foram, em total, seis informantes que possuíam estudos de nível básico. Os resultados ofereceram tanto a forma com o singtagma $a$ 
gente em função de sujeito, acompanhada do verbo em terceira pessoa do singular quanto a forma com sujeito implícito de primeira pessoa do plural aceitamos, obtendo o mesmo número de respostas, duas em cada caso, o que corresponde a 33,33\%. A forma com o pronome de primeira pessoa do plural concordando com o verbo "nós aceitamos" e a forma com sujeito implícito de terceira pessoa aceita obtiveram o mesmo número de respostas, uma em cada caso, o que significa o $16,67 \%$ para cada. Não foram registradas respostas para a forma agramatical nós aceita.

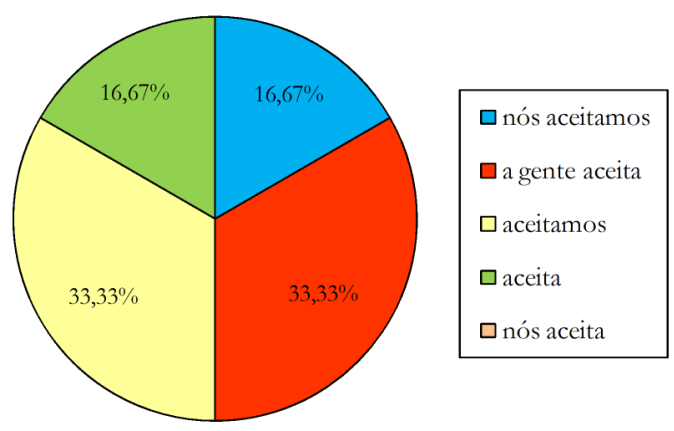

Gráfico 9 - Informantes com estudos de nível primário

\subsection{Informantes com estudos de nível secundário}

Os informantes pertencentes a este grupo foram o mais numeroso, em total 26. Também neste grupo houve o mesmo número de respostas para as duas opções mais frequentes. Tanto "nós aceitamos" quanto "a gente aceita" foram as formas escolhidas pelos informantes em nove ocasiões, resultando um $34,62 \%$ para cada um; em terceiro lugar se situa a forma "aceitamos", que foi a preferida por cinco informantes (19,23\%); com duas respostas obtidas segue em quarto lugar a forma "aceita" (7,69\%) e, em último lugar, a forma "nós aceita" foi dada por um dos informantes, o que supõe 3,85\%. Neste grupo deram-se todas as respostas possíveis. 


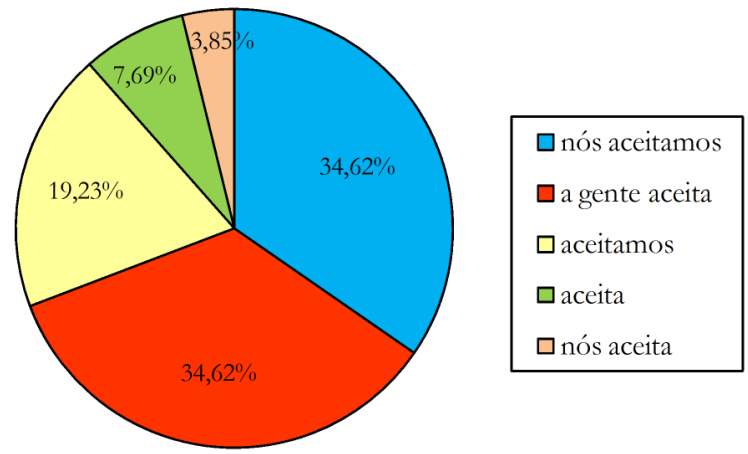

Gráfico 10 - Informantes com estudos de nível secundário

\subsection{Informantes com estudos de nível universitário}

Neste último grupo a forma escolhida pela maioria dos informantes foi "a gente aceita", com um número total de oito dados registrados (44,44\%); não muito longe, apenas menos um dado registrado ficou a forma "nós aceitamos" com sete registros; em terceiro lugar aparece a forma "aceitamos" com duas respostas e, para finalizar, houve um registro de "nós aceita" que, como ja foi comentado, chama muito a atenção em informantes deste nível.

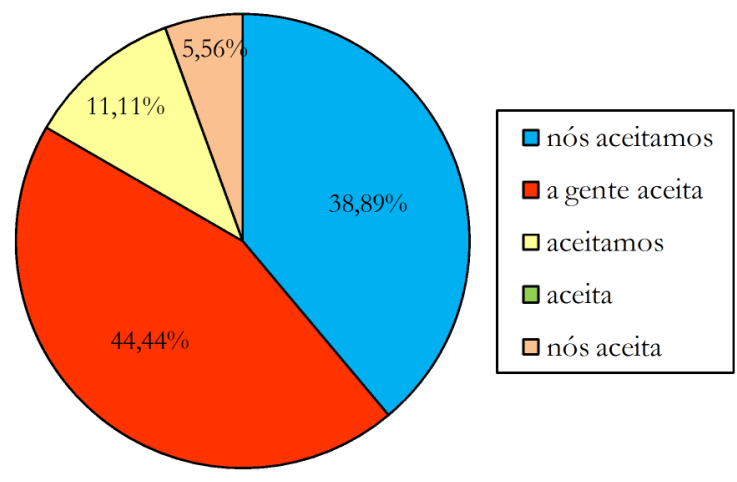

Gráfico 11 - Informantes com estudos de nível universitário 


\section{Conclusões}

Após a análise dos dados obtidos no inquérito aos informantes poderiamos estabelecer as conclusões seguintes:

- Existem cinco possibilidades diferentes de se referir à primeira pessoa do plural na fala de Londrina: Sujeito explícito "nós" e verbo em primeira pessoa do plural (nós aceitamos); sujeito explícito "a gente" e verbo em terceira pessoa do singular (a gente aceita); Sujeito tácito de primeira pessoa do plural, implícito na forma verbal com terminação em - mos (aceitamos); sujeito tácito de terceira pessoa do singular e verbo em terceira pessoa do singular (aceita) e sujeito explícito "nós" e verbo em terceira pessoa do singular (nós aceita).

- A forma preferida dos entrevistados foi a composta de sujeito explícito "a gente" e verbo em terceira pessoa do singular (a gente aceita), que atingiu o $40 \%$, seis pontos acima da forma canónica "nós aceitamos".

- A forma com sujeito explícito "a gente" e verbo em terceira pessoa do singular é a preferida pelos falantes mais novos $(57,14 \%)$, mas conforme avançamos na idade dos informantes vai se igualando a preferência com a forma que apresenta sujeito explícito "nós" e verbo em primeira pessoa do plural "nós aceitamos" e na faixa etária dos 30 aos 40 anos os informantes escolheram preferencialmente esta última forma $(53,85 \%)$.

- O nível de escolaridade dos informantes não define muito bem a escolha das respostas, existe praticamente um empate em todos os níveis entre a forma com sujeito explícito "nós" e verbo em primeira pessoa do plural (nós aceitamos) e a forma com sujeito explícito "a gente" e verbo em terceira pessoa do singular (a gente aceita). Podem-se achar construções agramaticales com sujeito explícito "nós" e verbo em terceira pessoa do singular (nós aceita) nos níveis de escolaridade mais altos. 


\section{Referências}

BECHARA, Evanildo. Moderna Gramática Portuguesa. São Paulo: Nova Fronteira, 2009.

CARDOSO, Suzana Alice Marcelino; FERREIRA, Viviane de Jesus. Os pronomes pessoais-sujeito no português do Brasil: nós e a gente segundo os dados do projeto Atlas Linguístico do Brasil. Projeto ALIB. Londrina: Eduel, 2009.

; FERREIRA, Carlota. A dialetologia no Brasil. São Paulo: Contexto, 1994.

CEGALLA, Domingos Paschoal. Novíssima gramática da língua portuguesa. São Paulo: Companhia Editora Nacional, 2008.

CINTRA, Lindley; CUNHA, Celso. Nova Gramática do Português Contemporaneo. São Paulo: Lexikon, 2008.

TEIXEIRA DE ALMEIDA, Nilson. Gramática Completa para Concursos e Vestibulares-Nova Ortografia. São Paulo: Saraiva, 2009. 